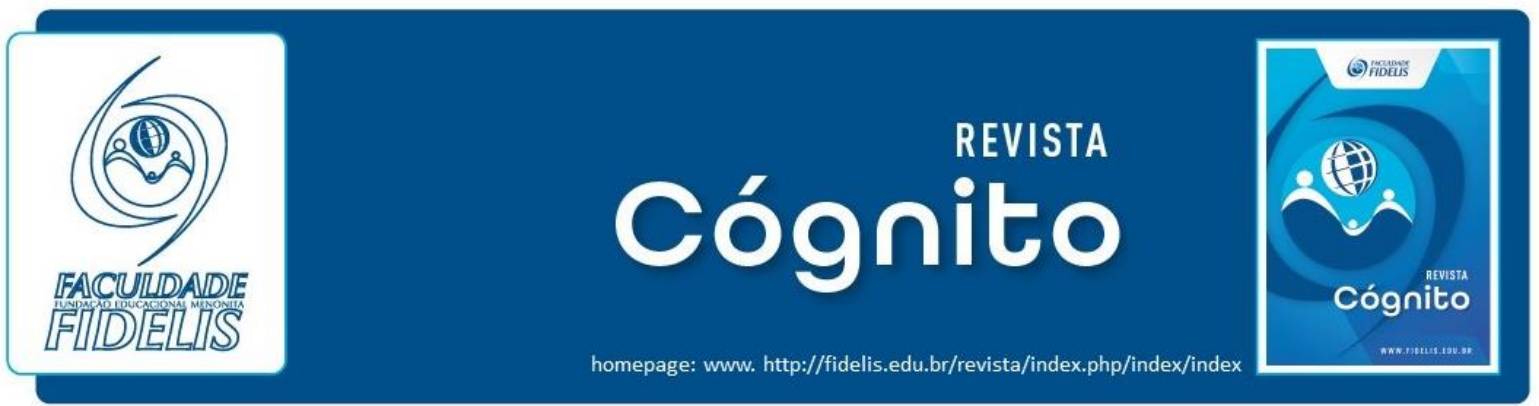

\title{
MISSÃO, REINO E IGREJA DE DEUS: ALINHANDO E COSTURANDO OS CONCEITOS
}

\author{
Clayton Lima de Souza ${ }^{1}$ \\ Arthur Wesley Dück ${ }^{2}$
}

\section{RESUMO}

Este artigo é uma apresentação resumida dos conceitos de "Missão de Deus" (missio Dei), "Reino (ou reinado) de Deus" e "Igreja". Isto foi feito de acordo com os textos bíblicos e com a literatura teológica produzida por diversos estudiosos no assunto, com o objetivo de compreende-los individualmente e entender como se inter-relacionam. Na presente pesquisa, constatou-se que a missão não é do indivíduo cristão e nem da igreja, mas que ambos são convidados a participar da missão em que Deus se empreendeu. Essa missão, iniciada logo depois da queda e que permeia todo o texto bíblico e consequentemente, toda a história da igreja, compreende o estabelecimento do seu reinado no mundo, não somente sobre o indivíduo, mas também sobre as instituições com o objetivo de restaurar tudo o que foi corrompido pelo pecado. Para tal, a igreja é a sua ferramenta de trabalho.

PALAVRAS CHAVE: Missão; Missão de Deus; Reino de Deus; Igreja; Igreja; Restauração.

\section{INTRODUÇÃO}

O presente artigo, tem por objetivo introduzir à discussão sobre a finalidade da igreja, seu lugar dentro do projeto de Deus e sua função determinada por Deus. A questão que motiva tal debate é se, como cristãos, não estamos corrompendo seu propósito e tornando-a ineficiente por falta de uma compreensão correta de seus fundamentos, dando lugar ao senso comum e alimentando dúvidas, tais como: é possível fazer parte do Reino de Deus e não da Igreja, e vicee-versa? E a missão é de quem, do cristão, da igreja, ou de ambos?

Para tal, foi realizada uma pesquisa sobre os fundamentos bíblico/teológicos de cada

\footnotetext{
${ }^{1}$ Bacharel em Teologia pela Faculdade Fidelis. teologia@ fidelis.edu.br

${ }^{2}$ Doutor em Estudos Interculturais - Trinity International University (EUA). Docente da Faculdade Fidelis arthur.duck@fidelis.edu.br
} 
um dos conceitos, pretendendo em primeiro lugar a correta definição do conceito de "missio Dei”, a missão a quem Deus envia a si mesmo com o objetivo de restaurar todas as coisas corrompidas pela entrada do pecado no mundo, e reconciliar consigo "todas as coisas". Em seguida, procurou-se delimitar o conceito de Reino de Deus, esclarecendo sua função de método divino para o cumprimento de Sua missão. Finalmente, buscou-se a definição de Igreja, como a ferramenta de Deus para a implantação de seu reinado. $\mathrm{O}$ artigo conclui com uma tentativa de desenhar de maneira prática como tais conceitos são interdependentes e como se explicam mutuamente.

\section{A "MISSÃO DE DEUS"}

O termo "missio Dei” surgiu no início do século vinte, das reflexões de teólogos como Karl Barth e Karl Hartenstein, mas sua lapidação contemporânea se deve principalmente a David Bosch que desenvolveu o conceito de que a missão é de Deus, e não somente no que diz respeito à tarefa, mas principalmente de um atributo divino em que "compreendeu-se a missão como derivada da própria natureza de Deus" (BOSCH, 2002, p. 467). Bosch destaca que a missão era compreendida ora como salvação do homem, ora como difusão cultural da cristandade ocidental, ora como o movimento expansionista da igreja; mas olhando para o tema da perspectiva da atividade realizada pela Trindade divina, ele afirma que "na tentativa de concretizar o conceito de missio Dei, era possivel dizer o seguinte: na nova imagem, a missão não é primordialmente uma atividade da igreja, mas um atributo de Deus" (BOSCH, 2002, p. 468). George (2006, p. 14) expande este conceito destacando a atividade proativa e redentora da Trindade, com o objetivo do estabelecimento do reinado de Deus, não somente na história da humanidade, mas em todo o universo. Isso não somente dá o crédito devido à atividade divina, como também coloca a igreja em seu devido lugar, pois como explica Bosch (2002, p. 468): "[...] nossas atividades missionárias só são autênticas na medida em que refletirem a participação na missão de Deus" Dück (2012, p. 683) destaca ainda que "[...] estamos agora mais conscientes de que precisamos de uma Missio Dei, que está mais focada em Deus do que no ser humano".

Desde os primeiros relatos em Gênesis, a ideia de que Deus tinha um projeto para o que havia criado, e que este projeto foi corrompido pelo pecado permeia toda a Escritura. Paulo ensina que toda a criação "geme", e por causa disso aguarda a ocasião de ser restaurada (Rm 8.19-22). Da mesma forma, essa restauração que Deus vem operando no decorrer da história é destacada na Bíblia como uma atividade proativa Dele. Isto é constatado desde o momento em 
que, logo após a Queda, passa pelo Éden à procura de Adão e Eva (Gn 3.8,9). É visto ainda na vinda do Filho, pelo qual todas as coisas foram criadas, no seu sacrifício vicário que promove o meio desta restauração $(\mathrm{Cl} 1.15-20)$. Tal atividade continua no papel da igreja, conforme será discutido adiante.

Uma base bíblica para esse conceito também é oferecida por Snyder (2004, p. 61-65) a partir da carta de Paulo aos Efésios em que o projeto de reconciliar com Deus não somente as pessoas, mas "todas as coisas, celestiais ou terrenas" (Ef 1.10) é apresentado. Ali, Paulo revela à igreja que ela não é um fim em si mesma, mas que ela faz parte de um projeto de Deus para toda a Criação.

Pode-se então definir o conceito de missio Dei como a atividade da Trindade no mundo e através da história, que envolve não somente a salvação do homem, mas a restauração de sua Criação como um todo. Bob Moffit (2011, p. 68) define isso considerando que essa missão divina inclui a redenção de tudo, inclusive do social e não somente do espiritual. $\mathrm{O}$ fato de Deus trabalhar em prol de sua Criação para consertar o que o pecado estragou, de "[...] transformar o mundo de forma que corresponda àquilo que imaginou para ele" (REIMER, 2011, p. 164), implica em que Ele não somente se revelou ao homem, mas também interferiu na história da humanidade com o objetivo de ser glorificado e ter seu reino estabelecido (BLACKABY; WILLIS JR., 2009, p. 59). Para isso, Deus envia e também é enviado como explica Bosch: "A doutrina clássica da missio Dei como Deus, o Pai, enviando o Filho, e Deus, o Pai e o Filho, enviando o Espírito foi expandida no sentido de incluir ainda outro 'movimento': Pai, Filho e Espírito Santo enviando a igreja para dentro do mundo" (BOSCH, 2002, p. 467).

Destacar o projeto divino e sua atividade não é apenas um assentimento intelectual, mas uma verdade que impulsiona a igreja à ação, pois “Quando somos convencidos a participar na obra de Deus percebemos que o Espírito já foi à nossa frente antes que pudéssemos fazer algo para participar nessa obra" (DÜCK, 2012, p. 9). Ao mesmo tempo, retira da igreja todo o mérito quando ela entende que "nunca pode deixar de lado que a iniciativa é divina e qualquer resposta humana precisa se basear sobre a missio Dei" (DÜCK, 2012, p. 10). A realização desse projeto se deve ao estabelecimento de seu reino na terra, assim como ele é estabelecido no céu (Mt 6.10).

\section{O "REINO DE DEUS"}

Se Deus tem um projeto para a restauração de tudo o que criou, isso implica em um método divino, ou seja, existe uma maneira pela qual Ele pretende fazer isso. É através da 
implantação de seu reino que Deus irá fazê-lo e por isso, é importante entender o que é e como funciona. A compreensão e a aplicação moderna do termo "reino" é geopolítica, definida tanto pelas delimitações geográficas de determinada nação quanto por sua demografia. Já o conceito bíblico da palavra, como explica George E. Ladd (2009, p. 84). desde a aplicação do verbete no seu original, é a de uma qualidade que pertence a alguém. Ainda segundo Ladd, o "significado primário" das palavras "malkuth" (hebraico) no Antigo Testamento e de "basileia" (grego) no Novo, refere-se à "dignidade, a autoridade e a soberania exercidas por um rei” e não a um domínio territorial ou político apenas. O reino de Deus, então, é o seu domínio sobre toda a criação. (idem, p. 84). ${ }^{3}$

Por este motivo, ao responder os fariseus sobre o reino de Deus, Jesus explica que ele não viria “de modo visível” e que "nem se dirá: ‘Aqui está ele', ou 'Lá está'; porque o Reino de Deus está entre vocês” (Lc 17.20,21). Apesar de não ser visível geopoliticamente, este reino é a concretização do que Deus se propôs desde o início com respeito à sua criação (CALDAS, 2007, p. 87), pois no que diz respeito ao governo de Deus que vem sendo estabelecido a partir de Jesus e como resultado de sua “misso Dei”, ele é, como explica Steuernagel (1993, p. 174), "[...] a porta da revelação dos planos de Deus para a história humana e a porta de acesso a Deus para toda a agonia e sofrimento humano".

Essa é então a dinâmica da missio Dei: Deus interfere no mundo e na história, estabelecendo o seu reino para assim promover a restauração da Criação corrompida pelo pecado. Caragounis (2012, p. 1061) explica que “O reino de Deus" está no âmago do ensino de Jesus. [...] era iminente e estava potencialmente presente em Jesus, em vez de ser uma vaga esperança futura, estando inextricavelmente ligado à sua pessoa e missão. Esse reino não é uma realização humana, mas realizado pelo próprio Deus. Sua ética é caracterizada pelo amor, mandamento principal e norteador dos demais mandamentos éticos, manifesto desde o ministério de Jesus, se desenvolvendo através da história e com um cumprimento pleno no futuro escatológico.

Finalmente, o conceito de reino de Deus implica em cidadãos deste reino. No que diz respeito aos conceitos já apresentados, este indivíduo que se identifica como tal "[...] o reconhece como rei e o estabelecimento de uma esfera humana em que seu poder gracioso se manifesta" (MARSHALL, 2012, p. 636). É nessa comunidade que, apesar de imperfeita, o lugar

\footnotetext{
${ }^{3}$ Por outro lado, talvez Ladd foi longe demais tentando separar o reinado e sobre o que o rei reina (a esfera do seu domínio) (McKNIGHT, 2014, p. 12). Um rei estabelece o seu reinado entre pessoas, sobre as estruturas malignas, sobre todas as esferas: isso é um reino geográfico, pois as regras do reino devem tomar conta de todas as dimensões da Criação.
} 
em que o “[...] seu poder gracioso está em operação” (MARSHALL, 2012, p. 636). Howard Snyder (2004, p. 28-29) destaca a necessidade de os cristãos terem uma compreensão clara a respeito do reino e do seu papel individual com respeito a ele e ao mundo ao seu redor. Para isso, ele identifica cinco elementos essenciais para ter essa consciência:

a) Uma ênfase na dimensão cósmica do evangelho: o cidadão do reino de Deus sabe que a salvação do indivíduo é o ponto central, mas não o único. Segundo o autor, ele tem a consciência de que essa salvação faz parte de um projeto maior e superior, a misso Dei, que busca a restauração de tudo, através da reconciliação operada em Jesus.

b) Uma recuperação da amplitude dinâmica da Palavra de Deus: no desenvolvimento da missão de Deus através do estabelecimento de seu reino no mundo, o "cidadão" compreende que Deus já se comunicou de diversas maneiras, e que ultimamente tem feito isso por meio de seu Filho (Hb 1.1). Crer na Bíblia, como infalível palavra inspirada por Deus, como fonte dos princípios e valores do reino e como um "lastro", um "padrão" através do qual a igreja julga a procedência da mensagem é fundamental, mas não se pode ignorar a maneira dinâmica como Deus se comunica, governa e orienta a sua igreja na direção de seus propósitos.

c) Uma recuperação de um senso de história: O olhar crítico sobre os fatos é aprimorado quando não são considerados apenas como uma sucessão de coincidências e fatalidades. O cidadão do reino tem em si a segurança de que Deus está no controle da história e o senso de responsabilidade com respeito às suas próprias ações e a relação delas com o projeto de Deus.

d) Uma nova ênfase na ética do reino: Cidadãos do reino de Deus vivem sob os valores do reino de Deus. Assim como Jesus no seu trabalho de estabelecimento do reino foi fiel em viver tais valores e sofreu as consequências disso, seus seguidores estão dispostos a segui-lo até o fim. Por esse motivo, não há espaço neste reino para discursos triunfalistas, mas para a consciência de que a salvação é gratuita, e que seguir a Jesus tem seu preço.

e) Finalmente, uma perspectiva cristã da cultura: o mandato do reino de Deus é ao mesmo tempo evangelístico e cultural, ou seja, Deus não está preocupado apenas com a igreja, mas com toda a Criação. Por esse motivo, a atenção do cidadão do reino não está voltada apenas para as questões eclesiásticas, mas para todas as preocupações da vida, da sociedade e do mundo. Todos os elementos da Criação e todas as modalidades de interação social precisam ser alcançados e restaurados na implantação do reino, ou seja, precisam ser submetidos ao governo de Cristo.

Concluindo, Snyder deixa claro que isso exige mais do que pregar a salvação da "alma", mas um comprometimento integral com a causa do reino e seu estabelecimento no 
mundo. Exige também e consequentemente, um posicionamento do cristão como cidadão do reino em trabalhar efetivamente para que tudo esteja debaixo do governo de Deus, a começar pelas instituições das quais faz parte como sua família, sua comunidade, etc. Snyder também está preocupado com a atualidade, a relevância e a aplicabilidade da mensagem divina para o mundo atual. Está igualmente preocupado em que, compreendendo-se parte de algo que Deus já está fazendo no mundo, como sua ferramenta, o cidadão do reino possa vê-lo e ouvi-lo também no mundo, atendendo seu chamado que ecoa nas necessidades do seu bairro, sua cidade, seu país.

O autor aprofunda sua tese de que nem o cristão nem a igreja podem estar preocupados apenas consigo mesmos. Ele alerta para a nossa responsabilidade como propagadores do reino e para as consequências de nossas atitudes em relação a isso. Tudo o que fazemos e falamos deve estar sob esta preocupação. Ser cidadão do reino não diz respeito apenas a direitos, mas principalmente deveres relacionados ao projeto de Deus, e acrescenta ainda o fator do sofrimento como uma das consequências de assumir tal posicionamento.

Essa consciência de reino de Deus produz uma nova cosmovisão para o cristão e consequentemente para a igreja, que passa a olhar para o mundo não como um "fosso" de onde precisamos resgatar as almas perdidas, mas como a Criação de Deus que, à medida que seu reino vai sendo estabelecido através da sua comunidade de salvos e transformados, é colocada sob seu governo e restaurada. O reino de Deus é uma nova ordem em que nela Deus governa a ética nos relacionamentos, as práticas sócio-políticas, a dinâmica nos negócios, as questões ecológicas e em todos os aspectos da vida e da existência, e Ele pretende realizar isso tendo a sua igreja como ferramenta principal.

\section{A "IGREJA DE DEUS"}

O presente artigo trata da igreja em termos de "princípios" que extraímos das Escrituras e que são aplicáveis a qualquer época e cultura. O que o Novo Testamento apresenta sobre a igreja não é um modelo do tipo "como é uma igreja" ou "como se faz uma", mas oferece estes princípios que precisam ser compreendidos dentro de seu contexto histórico-cultural para assim, serem aplicados em nosso próprio contexto. Em Atos 2.41-47, Lucas apresenta a igreja de uma maneira muito especial:

Os que aceitaram a mensagem foram batizados, e naquele dia houve um acréscimo de cerca de três mil pessoas. Eles se dedicavam ao ensino dos apóstolos e à comunhão, ao partir do pão e às orações. Todos estavam cheios de temor, e muitas maravilhas e 


\begin{abstract}
sinais eram feitos pelos apóstolos. Todos os que criam mantinham-se unidos e tinham tudo em comum. Vendendo suas propriedades e bens, distribuíam a cada um conforme a sua necessidade. Todos os dias, continuavam a reunir-se no pátio do templo. Partiam o pão em suas casas, e juntos participavam das refeições, com alegria e sinceridade de coração, louvando a Deus e tendo a simpatia de todo o povo. E o Senhor lhes acrescentava todos os dias os que iam sendo salvos. (NVI).
\end{abstract}

Ao ler esse texto, é possível verificar que as palavras que destacam as atividades da igreja remetem o leitor, como explica Marshall (2012, p. 638), à vida e às atividades do próprio Cristo quando em seu ministério terreno. Quando a igreja do Novo Testamento se perguntava sobre qual a sua função, papel e atividade, ela olhava apenas para Jesus. Comentando o versículo 42, Hayes (2002, p. 29) propõe ser esse texto uma descrição resumida da igreja primitiva, que se caracterizava especialmente pela comunhão (koinonia). A igreja do Novo Testamento demonstrava então, ter assimilado a ideia de Jesus, pois replicava a sua proposta, porém sem se deter a especificações de formato. Hayes ainda destaca que a palavra koinonia faz referência a uma "[...] comunidade de crentes generosos fazendo o bem a todos, especialmente aos que pertencem à família de crentes (Gl 6.10)" (HAYES, 2002, p. 30). Justamente por causa da comunhão que experimentavam, ela pode ser descrita como uma comunidade em ação.

Algumas características importantes da igreja do Novo Testamento são pontuadas por Shenk e Stutzman (1995, p. 76-77) e podem ser úteis nesta tarefa de conhecer os princípios e valores desta igreja, como segue:

a) Eles estavam juntos todos os dias, e essa reunião constituía a principal atividade da igreja. Essa reunião regular, além do propósito da adoração e do estudo das Escrituras em comunidade, era importante para reforçar o conceito de unidade e apoio mútuo. Isso, porém, não significa que a igreja se via como um grupo fechado, mas expressava a necessidade que tinham de unidade.

b) Os apóstolos os ensinavam tudo o que haviam aprendido com Jesus. Desde as referências ao Antigo Testamento até às novas aplicações recebidas do Mestre, passando pelo seu exemplo e seu sacrifício, cada novo crente era adequadamente doutrinado.

c) Inicialmente derrubando a barreira do gênero e mais tarde, também a da raça, a igreja do Novo Testamento experimentava um profundo sentimento de irmandade e principalmente de aceitação promovida pela atuação do Espírito Santo.

d) A necessidade de um era a necessidade de todos e por isso, o repartir era mais do que uma atividade ou uma ação social: era um reflexo do amor que havia entre eles. Não havia 
um programa de assistência social da igreja, mas o desejo mútuo e profundo de que todos estivessem supridos em suas necessidades.

e) A prática da Eucaristia os lembrava de quem era Jesus e do lugar central que ele ocupava na igreja, e as refeições comunitárias, por sua vez, os lembravam de quem eles eram e do tipo de relacionamento deveriam desenvolver entre si.

f) A oração era a respiração da igreja, e precedia cada decisão e ação. A igreja do Novo Testamento era uma igreja que orava, pois dependia totalmente da intervenção de Deus e da direção de seu Espírito Santo.

g) O que a igreja fazia era a expressão do amor e da alegria que permeava e enchia a comunidade e consequentemente transbordava para fora dela.

h) A igreja acontecia em pequenos grupos que se multiplicavam pelo testemunho pessoal. Seu crescimento era natural e a proclamação era ousada.

i) Eram comunidades que temiam a Deus e que levavam a sério o compromisso que haviam feito com Ele e com seus irmãos. Por isso, a disciplina era um ponto importante da conduta desta igreja.

É importante destacar que os primeiros cristãos, a maioria deles judeus, passaram a se reunir no modelo das sinagogas judaicas, com a inclusão de mulheres e crianças, como nos explica Ralph D. Winter (2009, p. 246), e mais tarde, incluiriam também os não-judeus. Isso mostra que a intenção não era criar um novo modelo padronizado, mas aproveitar uma estrutura que era boa, familiar e própria para o seu contexto. Aliás, aproveitar o que já existia na cultura e atribuir uma nova conotação para realização de seus propósitos já havida sido praticado por Jesus, como nos casos do Batismo e da Ceia. Desde o início então, a igreja se adapta e se contextualiza sem negociar seus valores.

Deste fato, também é possível extrair outro princípio importante: ao congregar juntos homens e mulheres, jovens e velhos, a igreja se parece muito com uma família biológica, e isso se torna um valor para as igrejas que surgiram depois (WINTER, 2009, p. 246).

\section{4 "COSTURANDO" OS CONCEITOS}

A salvação do homem está no centro da missio Dei, mas o propósito divino é maior: é a redenção de toda Criação. Por esse motivo a igreja não somente evangeliza, mas tem a sua visão ampliada. Snyder qualifica a igreja como "agente" e "instrumento" de Deus em sua missão, e por isso, "[...] a missão da igreja é mais que evangelizar" (SNYDER, 2001, p. 188). Em outra obra, Snyder chega a dizer que a participação da igreja é "essencial" (SNYDER, 2004, 
p. 25), pois seu papel é o de interface e de veículo de comunicação de Deus e é através dela que Ele pretende desenvolver seu projeto.

Em Efésios 3.10, Paulo deixa clara essa dimensão de atuação da igreja quando afirma que através dela, a "multiforme sabedoria de Deus" seria conhecida dos "poderes e autoridades". É através da igreja que em Cristo, Deus faz o seu trabalho de restauração (2Co 5.19). Roxburg e Romanuk afirmam que

\footnotetext{
Deus tem um grande propósito para toda a Criação. A igreja foi chamada para a vida, para ser tanto o meio dessa missão quanto uma antecipação de onde Deus está convidando toda a criação para ir. Assim como o seu Senhor é um Deus em forma de missão, a comunidade do povo de Deus existe não para si, mas para o bem da obra. A missão não é, portanto, um projeto ou programa que algumas pessoas na igreja fazem de vez em quando (como em uma "viagem missionária", um "orçamento missionário", e assim por diante); a própria natureza da Igreja é ser povo missionário de Deus. Usamos a palavra missional para marcar esta grande diferença. (ROMANUK; ROXBURGH, 2006, p. xv).
}

Aqui, Jesus é “o modelo" para a igreja (Mt 20.28) em que "o estilo da missão da igreja é, dessa forma, firmemente estabelecido no molde do serviço" (HAYES, 2002, p. 185). Ela é a continuadora da obra de Cristo à medida que replica a maneira como Ele serviu e contribuiu para a missão.

Portanto, a relação da igreja com a missio Dei é, na imitação de Cristo, fazer parte do projeto de Deus com seu serviço, o que provoca nela um novo posicionamento e "[...] exige o ministério mais amplo da igreja: "pregar boas novas aos pobres... proclamar liberdade aos presos e recuperação da vista aos cegos... libertar os oprimidos e proclamar o ano da graça do Senhor' (Lc 4.18,19)" (SNYDER, 2004, p. 70). Isso significa que evangelizar não é a tarefa última da igreja, mas faz parte de um papel maior a ser desempenhado: o de agente transformador da realidade, conformando-a aos valores do reino de Deus. Isso também não reduz o valor do evangelismo para a igreja, mas faz com que ela deixe (como o é em muitos casos), de ser algo alienado e dissociado da vida e do cotidiano.

Compreendendo o reino de Deus como a instauração de seu governo sobre a sua criação, incluindo obviamente o homem e todas as suas instituições, e a igreja como a ferramenta para que isso se realize, conclui-se, portanto, que a igreja faz parte do reino e não de outra forma. Porém, Agostinho de Hipona popularizou no cristianismo a ideia de que igreja e reino de Deus são a mesma coisa (RYRIE, 2004, p. 459), e por esse motivo, por muito tempo a autoridade sobre todas as instituições humanas estava nas mãos do clero. 
A igreja é formada pelos súditos do reino, que estão sob a autoridade do Rei Jesus e que vivem de acordo com os valores desse reinado. Eles cooperam para que outros também sejam cidadãos deste e para fazer com que a vontade do Rei seja feita. Porém, esse reinado não se limita à igreja, pois ele é "[...] poder, autoridade, liderança e governo de Jesus dentro e fora das pessoas, que se torna visível por meio de sinais concretos e mostram que Jesus é o Messias." (MUZIO, 2010, p. 93). No estabelecimento do reino, a igreja acaba por ter de confrontar o reino de Satanás, pois "o Reino de Deus tem a ver com a presença dinâmica do poder redentor de Deus confrontando as forças do mal e restaurando a vida.” (MUZIO, 2010, p. 93). Aonde a luz chega a escuridão é dissipada e a igreja como luz entende e assume o seu papel, como explica Colson:

Em toda ação, estamos fazendo uma de duas coisas: ou estamos ajudando a criar o inferno na terra ou trazendo para cá o antegozo do céu. Ou estamos contribuindo para a condição despedaçada do mundo ou estamos participando com Deus na transformação do mundo para refletir sua justiça. Ou estamos fazendo avançar o regime de Satanás ou estamos estabelecendo o Reino de Deus (COLSON; PEARCEY, 2000, p. 31).

A importância de a igreja entender seu papel com respeito ao estabelecimento do reinado de Deus é que não há meio termo neste assunto. Ou serve-se a Deus ao agir-se ou servese ao diabo ao omitir-se. Deus quer que seu reinado alcance o mundo para transformá-lo. Onde seu reinado é estabelecido, o diabo não pode mais dominar por que agora as pessoas e seu meio são transformados. Agora é Deus quem governa e restaura.

A igreja não é o reino de Deus, mas não se trata de duas coisas completamente distintas. A igreja é "[...] o povo do reino de Deus, a 'comunidade escatológica' que já vive sob o domínio de Deus e o proclama." (SNYDER, 2004, p. 65), ou como mais detalhadamente explica Grudem:

Portanto, não devemos identificar o reino de Deus com a igreja (como na teologia católica romana), nem ver o reino de Deus como inteiramente futuro, algo distinto da era da igreja (como na teologia dispensacionalista mais antiga). Em vez disso, devemos reconhecer que há uma relação próxima entre o reino de Deus e a igreja. À medida que a igreja proclama as boas novas do reino, pessoas virão para a igreja e começarão a experimentar as bênçãos do domínio de Deus em suas vidas. (GRUDEM, 1999, p. 724).

Grudem ainda destaca que aqueles que fazem parte da igreja, pela fé podem 
experimentar a realidade do governo de Deus e a vitória sobre o pecado, vivendo sob o domínio do Espírito Santo, mesmo que tais realidades se concretizem plenamente no futuro (GRUDEM, 1999, p. 724). Porém, é importante destacar que essa experiência vivenciada no ambiente "igreja" (instituição) pode e deve ser replicada para fora dela, por todos os ambientes onde ela, como ferramenta para a instalação do reinado de Deus, alcança.

A pergunta é: será que somente aqueles que passam a fazer parte da igreja são os que podem experimentar e usufruir da manifestação do reinado de Cristo? Rubens Muzio diz que a igreja pode compartilhar as bênçãos do reino de Deus com a comunidade (MUZIO, 2010, p. 57), pois é ali que essa igreja trabalha no estabelecimento do reino. A graça, a paz e a justiça do reino de Deus se manifestam no mundo, e igreja é a ferramenta de Deus para que isso aconteça.

É preciso entender bem esse conceito, pois boa parte dos princípios missionais tem como foco essa compreensão. Na confusão conceitual com o reinado, a Igreja não somente se isolou do mundo como deixou de ter qualquer utilidade ou oferecer qualquer benefício para quem está de "fora" dela. Nessa visão, quem está dentro do reinado/igreja é quem pode ser beneficiado pelo governo de Deus, quando na verdade, onde Deus estabelece seu reinado através de Sua Igreja, todos são beneficiados, membros da igreja ou não.

Assim como o alvo do amor de Deus é o mundo esse deve ser o alvo da igreja. Sendo assim, se esta igreja é serva de Deus, consequentemente também é serva do mundo. Em primeiro lugar, como imitadora de Cristo a relação da igreja com o mundo acontece da mesma maneira como foi com seu Mestre: encarnando (Jo 1). A maneira como Jesus cumpriu seu papel na instauração do seu reinado, não foi como uma entidade espiritual e alheia à realidade e à cultura de sua época, mas foi nascendo como um deles e compartilhando a vida deles. Quando a igreja assimila este conceito, começa a entender que pode e deve fazer parte da cultura ao seu redor sem, no entanto, negociar suas convicções de fé. Ela aprende que precisa fazer parte da vida das pessoas às quais quer alcançar, para que através da compreensão e valorização de sua cultura e da maneira como entendem a vida, possa pregar um evangelho genuíno e ao mesmo tempo compreensível para aquela determinada comunidade. Por esse motivo, as Escrituras não oferecem um modelo estático de igreja, pois como alerta Snyder:

As estruturas devem ser compatíveis com as formas culturais da sociedade em que a igreja se encontra. Por esse motivo, as estruturas da igreja não podem ser transplantadas de maneira acrítica de uma cultura para outra, sem que se causem sérios problemas e equívocos fundamentais no que diz respeito à verdadeira natureza da igreja. (SNYDER, 2004, p. 43) 
O chamado da igreja para estar encarnada na sociedade é compreendido quando ela entende que, não pode ser um "corpo estranho" na comunidade, mas ser diferente ao fazer a diferença, e isso pode e deve ser feito do lado de dentro, do mesmo jeito que Jesus fez: vivendo na cultura e entendendo-a, para assim poder oferecer a sua opção contra cultural. Em segundo lugar, a relação da igreja com o mundo é que, assim como Cristo foi enviado, seus discípulos também o são (Jo 20.21). Para participar do projeto de Deus, a igreja é enviada ao mundo. A igreja através das pessoas que a compõe, são os "agentes ativadores de transformação" (MOFFIT, 2011, p. 150), mas para isso, propõe-se que ela vá para fora de seus muros.

\section{CONCLUSÃO}

Definir e explicar conceitos é algo tão complexo quanto demonstrá-los na prática. Isso se aplica, é claro, à igreja, não somente como instituição, mas principalmente como ideia divina. A dificuldade começa pela falta de entendimento de que, a igreja que Jesus idealizou não tem uma missão particular, não é ela sozinha o reino de Deus e não existe como um fim em si mesma, e se intensifica quando ignora a ideia de que ela é a ferramenta que Deus criou e usa para, através da instituição de seu reinado no mundo em todos os seus aspectos, opere sua missão máxima de restaurar e reconciliar com Ele mesmo toda a sua criação.

A compreensão do projeto de Deus, deve nos levar à reflexão de como somos e fazemos igreja, se nossos prédios, departamentos e programas estão de acordo com essa configuração, se nossos líderes tem consciência deste alvo e desenvolvem seus projetos de acordo com ele e se como povo de Deus, cidadãos do seu reino, vivemos s servimos para esse fim.

\section{REFERÊNCIAS}

BLACKABY, H. T. Em missão com Deus. In BRADFORD, K. D.; WINTER, R. D.; HAWTHORNE, S. C. (Ed.). Perspectivas no movimento cristão mundial. São Paulo: Vida Nova, 2009, p. 59-62.

BOSCH, D. J. Missão transformadora: mudanças de paradigma na teologia da missão. São Leopoldo: Sinodal, 2002.

CALDAS, C. Fundamentos da teologia da Igreja. São Paulo: Mundo Cristão, 2007.

CARAGOUNIS, C. C. Reino de Deus 1: Evangelhos. In: REID, D. G. (Ed.). Dicionário teológico do Novo Testamento. São Paulo: Vida Nova, 2012, p. 1061 - 1077. 
COLSON, C.; PEARCEY, N. E agora, como viveremos? Rio de Janeiro: CPAD, 2000.

DÜCK, A.W. Apostila de Teologia Sistemática.doc. Curitiba, 2012. 1 arquivo (2,83 mb).

DÜCK, A.W. Apostila de Teologia bíblica da missão.pdf. Curitiba, 2012. 1 arquivo (2,05 $\mathrm{mb})$.

GEORGE, S. K. Participantes da graça: parceria na missão de Deus. São Leopoldo: Sinodal, 2006.

GRUDEM, W. A. Teologia sistemática. São Paulo: Vida Nova, 1999.

HAYES, E. Igreja: corpo de Cristo no mundo de hoje. São Paulo: Hagnos, 2002.

LADD, G. E. O evangelho do reino. In: BRADFORD, K. D.; WINTER, R. D.; HAWTHORNE, S. C. (Ed.). Perspectivas no movimento cristão mundial. São Paulo: Vida Nova, 2009, p. 82 $-97$.

MARSHALL, I. H. Igreja 1: Evangelhos. In: REID, D. G. (Ed.) Dicionário teológico do Novo Testamento. São Paulo: Vida Nova, 2012, p.635-639.

McKNIGHT, Scot. Kingdom Conspiracy: returning to the radical mission of the local church. Grand Rapids: Baker, 2014. Edição do Kindle.

MOFFIT, B. Se Jesus fosse o prefeito: transformação e a Igreja local. Phoenix: Harvest, 2011.

MUZIO, R. O DNA da igreja: comunidades cristãs transformando a nação. Curitiba: Esperança, 2010.

REIMER, J. Abraçando o mundo: Teologia de implantação de igrejas relevantes para a sociedade. Curitiba: Esperança, 2011.

ROMANUK, F.; ROXBURGH, A. The missional leader: equipping your church to reach a changing world. San Francisco: Jossey-Bass, 2006.

RYRIE, C. C. Teologia básica: Ao alcance de todos. São Paulo: Mundo Cristão, 2004.

SHENK, D. W.; STUTZMAN, E. R. Criando comunidades do reino: Modelos neotestamentários da implantação de Igrejas. Campinas: Cristã Unida, 1995.

SNYDER, H. A. Vinho novo, odres novos: vida nova para a igreja. São Paulo: ABU, 2001.

SNYDER, H. A. A comunidade do rei. São Paulo: ABU, 2004.

STEUERNAGEL, V. Obediência missionária e prática histórica. São Paulo: ABU, 1993.

WINTER, D. W. As duas estruturas da missão redentora de Deus. In: K. D. BRADFORD; R. D. WINTER; S. C. HAWTHORNE (Ed.). Perspectivas no movimento cristão mundial. São Paulo: Vida Nova, 2009. 